\title{
Análise das Relações entre o Financiamento Público e o Crescimento do Mercado de Planos de Saúde no Brasil
}

\section{Analysis of the Relationship between Public Funding and Market Growth of Health Plans in Brazil}

Debora Maltez Farias Costa* Garibaldi Dantas Gurgel Júnior* * Idê Gomes Dantas Gurgel** *

\begin{abstract}
Resumo: Durante muitos anos o Sistema Único de Saúde não possuiu fontes estáveis de financiamento. Em paralelo, o mercado de planos vem sendo incentivado por meio da renúncia fiscal com despesas de saúde. O presente estudo objetiva compreender as relações entre o financiamento do Sistema Único de Saúde, a renúncia fiscal com despesas de saúde e o mercado brasileiro de planos de saúde no período de 1990 a 2008. Trata-se de um estudo de caso, com abordagem qualitativa, no qual foi realizada uma triangulação de fontes de dados coletados a partir de entrevistas, documentos e bases de dados oficiais. Os resultados mostram o crescimento do mercado brasileiro de planos de saúde no período de 1990 a 2008, o incremento da renúncia fiscal referente às despesas médicas, além do pequeno aumento de gastos diretos na saúde em relação ao PIB, que juntos parecem distanciar o país de concretizar o projeto solidário de saúde para todos, escrito na constituição cidadã.
\end{abstract}

Palavras-chave: Planos de pré-pagamento em saúde. Financiamento em saúde. Isenção fiscal.

Abstract: For many years the Unified Health System lacked stability of funding. In parallel, the insurance and health plans market have been encouraged by tax exemption on medical expenses. This study aims to understand the relationship between the funding mechanism of the Unified Health System, the tax exemption with health expenditure and the Brazilian health plans market from 1990 to 2008. This is a case study with a qualitative approach, which was performed in a triangu-

\footnotetext{
* $\quad$ Especialista em Regulação de Saúde Suplementar-ANS/PE. Mestre em Saúde Pública. E-mail: deboramaltez@yahoo.com.br

** Pesquisador do CPqAM/Fiocruz. Médico e doutor em Políticas Públicas. E-mail: gurgel@cpqam. fiocruz.br

*** Pesquisadora do CPqAM/Fiocruz. Médica e doutora em Saúde Pública. E-mail: ideg@cpqam. fiocruz.br
} 
lation of data sources collected from interviews, documents and official databases. The results show the growth of the Brazilian health plans in the period 1990 to 2008, the increase in tax exemption related to medical expenses, as well as the small increase in direct costs on health to GDP, which together seem to push the country away from implement the health solidarity project for all, written in the constitution of citizenship.

Keywords: Prepaid health plans. Health care funding. Tax exemption.

JEL Classification: I13; H51; H20.

\section{Introdução}

O Sistema Único de Saúde (SUS) desenvolveu-se em um contexto de crise fiscal profunda (PEREIRA FILHO, 2004) e sua implementação foi desviada por reformas do setor público (DUARTE, 2000), comumente associadas à ascensão do pensamento neoliberal na década de 1990, contrário ao Estado intervencionista e de bem-estar. À época da criação do SUS, já existia um setor privado de dimensões importantes tanto em unidades hospitalares, quanto em empresas de planos de saúde. Desse modo, o sistema de saúde brasileiro adquiriu um caráter peculiar, consubstanciado numa imbricação estrutural entre o público e o privado (PORTO; SANTOS; UGÁ, 2008) representado, de um lado, pelo Sistema Único de Saúde universal e do outro, pelo Sistema de Saúde Suplementar com várias modalidades de asseguramento e provisão de serviços em caráter privado e exclusivo.

O SUS tem mais de vinte anos e o que se observa é que sua implementação afasta-se dos preceitos constitucionais, baseado no Modelo de Seguridade Social, a exemplo do claro contraste entre o seu financiamento precário e seus princípios doutrinários (BAHIA, 2005), como a universalidade de acesso, integralidade e equidade. Além disso, os benefícios tributários referentes aos gastos com planos de saúde, que consistem em renúncia de arrecadação fiscal em favor de pessoas físicas e jurídicas que declaram despesas com saúde, configuram uma forma de financiamento público para o mercado de planos (ANDRADE, 2004).

Acredita-se que o estudo do mercado de planos de saúde e sua interface com o financiamento do SUS e os benefícios tributários possibilitam maior compreensão da política de saúde de Estado adotada no país.

\section{Percurso Metodológico}

Trata-se de um estudo de caso, com abordagem qualitativa. O caso é o mercado brasileiro de planos de saúde, cujo crescimento foi analisado à luz do financiamento do SUS e da renúncia fiscal com despesas de saúde. O período de estu- 
do foi de 1990 a 2008, com abrangência no Brasil. Foi realizada uma triangulação de fontes de dados coletados a partir de entrevistas, documentos e bases de dados oficiais. As entrevistas e os documentos foram analisados por meio da técnica de Análise de Conteúdo na perspectiva de Bardin (2004).

A pesquisa documental e as entrevistas, as quais ocorreram, respectivamente, nos períodos de setembro/2009 a março/2010 e de novembro/2009 a dezembro/2009, foram realizadas com as seguintes instituições/atores do mercado brasileiro de planos de saúde:

a) governo: Ministério da Saúde (MS), Ministério da Fazenda (MF), Superintendência de Seguros Privados (Susep) e Agência Nacional de Saúde Suplementar (ANS);

b) planos de saúde: Associação Brasileira de Medicina de Grupo (Abramge), Confederação Nacional das Cooperativas Médicas (Unimed do Brasil), União Nacional das Instituições de Autogestão em Saúde (Unidas) e Federação Nacional de Saúde Suplementar (Fenasaúde);

c) usuários de planos de saúde: Central Única dos Trabalhadores (CUT) e Instituto Brasileiro de Defesa do Consumidor (Idec);

d) prestadores: prestadores hospitalares - Confederação Nacional de Saúde, Hospitais, Estabelecimentos e Serviços (CNS) e prestadores médicos - Conselho Federal de Medicina (CFM);

e) Conselho Nacional de Saúde (CNS).

Os documentos de domínio público estavam disponíveis em endereços eletrônicos das instituições pesquisadas ou foram obtidos durante realização de entrevistas. O Quadro 1 mostra a quantidade de documentos analisados por entidade.

Quadro 1 - Número de documentos analisados por entidade pesquisada

\begin{tabular}{|c|c|c|}
\hline \multicolumn{2}{|c|}{ Entidade } & $\begin{array}{c}\text { Número de docu- } \\
\text { mentos }\end{array}$ \\
\hline \multirow{4}{*}{ Governo } & Ministério da Saúde & 9 \\
\cline { 2 - 3 } & Ministério da Fazenda & 4 \\
\cline { 2 - 3 } & Susep 1 & 11 \\
\cline { 2 - 3 } & ANS & 10 \\
\hline \multirow{3}{*}{ Planos de saúde } & Abramge & 6 \\
\cline { 2 - 3 } & Unimed do Brasil & 48 \\
\cline { 2 - 3 } & Unidas ${ }^{2}$ & 10 \\
\cline { 2 - 3 } & Fenasaúde & 12 \\
\hline \multirow{2}{*}{ Usuários de planos de saúde } & CUT & 12 \\
\cline { 2 - 3 } & Idec & 15 \\
\hline \multirow{2}{*}{ Prestadores } & Confederação Nacional de Saúde, Hospitais, Estabelecimentos e & \\
\cline { 2 - 3 } & Serviços & 19 \\
\cline { 2 - 3 } & CFM & 23 \\
\hline
\end{tabular}

Fonte: Elaboração própria.

Nota: 1 - A Susep - está ligada ao MF e era a instituição responsável pela regulação dos seguros saúde antes da criação da ANS, em 2000. 2 - A Unidas é resultado da fusão, ocorrida em 2002, do Comitê de Integração de Entidades Fechadas de Assistência à Saúde (Ciefas) com a Associação Brasileira de Autogestão em Saúde (Abraspe). 
As entrevistas foram realizadas nos Estados de Pernambuco, São Paulo e Rio de Janeiro, além do Distrito Federal. Também foram entrevistados pesquisadores com notório conhecimento sobre o tema abordado neste estudo, identificados como pesquisador 1 e 2. No total, foram realizadas 14 entrevistas. Todos os sujeitos foram informados da condição de uma autora ser funcionária da Agência Nacional de Saúde Suplementar.

A coleta nas bases de dados foi feita em sistemas de informação, também de domínio público, constantes em endereços eletrônicos pertencentes à ANS, ao Ministério da Saúde, à Secretaria da Receita Federal/Ministério da Fazenda e ao Instituto Brasileiro de Geografia e Estatística (IBGE). O período de coleta foi de junho/2009 a agosto/2009.

O estudo que originou este artigo foi aprovado pelo Comitê de Ética do CPqAM/Fiocruz.

\section{Resultados e Discussão}

O crescimento do mercado, no que se refere à evolução comparativa da receita de cada modalidade de planos de saúde nos anos de 2001 e 2008, mostra que as únicas operadoras a terem desempenho melhor foram as operadoras odontológicas (Tabela 1). Particularmente, em relação às autogestões, como estas só foram obrigadas a informar suas receitas a partir de 2007, obtém-se percentuais muito altos comparativamente.

Em relação ao crescimento da despesa de cada modalidade, comparando os anos de 2001 e 2008 (Tabela 2), verifica-se que a odontologia de grupo e a cooperativa odontológica novamente se destacaram, neste caso, em virtude do crescimento da sua despesa ter sido maior que o crescimento da despesa do setor. Novamente em relação às autogestões, obtêm-se percentuais muito altos por fatores já explicitados.

Verificou-se que o setor de planos de saúde brasileiro no período de 2001 a 2008 apresentou crescimento da receita menor que o crescimento da despesa total. Tal fato pode estar relacionado aos altos custos da assistência médica, gerados pelo envelhecimento da população, que causa aumento da ocorrência de doenças crônico-degenerativas e demanda por serviços. Além disso, os custos elevados estão associados ao desenvolvimento e incorporação de novas tecnologias, com efeito muitas vezes cumulativo, pois não dispensa o uso de tecnologias tradicionais (DUARTE, 2000).

As modalidades que tiveram comportamento inverso em relação ao crescimento de receita/despesa do setor foram as seguradoras especializadas em saúde, odontologia de grupo e cooperativas odontológicas, cujo crescimento da receita foi maior que o da despesa. As operadoras odontológicas também tiveram no pe- 
ríodo de 2000 a 2008 desempenho positivo no crescimento do número de usuários, os quais aumentaram $228,87 \%$ nas cooperativas odontológicas e $281,05 \%$ nas empresas de odontologia de grupo, conforme Tabela 3 (AGÊNCIA NACIONAL DE SAÚDE SUPLEMENTAR, 2009b).

Tabela 1 - Receita das operadoras por ano e crescimento (\%) segundo modalidade (R\$ milhões). Período: 2001-2008

\begin{tabular}{cccc}
\hline Modalidade & $\mathbf{2 0 0 1}$ & $\mathbf{2 0 0 8}$ & Crescimento (\%) \\
\hline Cooperativa Médica & 8.249 & 21.023 & 155 \\
\hline Medicina de Grupo & 6.597 & 17.184 & 160 \\
\hline $\begin{array}{c}\text { Seguradora Especiali- } \\
\text { zada em Saúde }\end{array}$ & 5.398 & 11.054 & 105 \\
\hline Autogestão & 420 & 6.716 & $1.499^{*}$ \\
\hline Filantropia & 1.112 & 1.987 & 79 \\
\hline $\begin{array}{c}\text { Odontologia de } \\
\text { Grupo }\end{array}$ & 218 & 765 & 251 \\
\hline $\begin{array}{c}\text { Cooperativa Odonto- } \\
\text { lógica }\end{array}$ & 127 & 358 & 182 \\
\hline Setor & 22.122 & 59.088 & 167 \\
\hline
\end{tabular}

Fonte: Adaptado de Agência Nacional de Saúde Suplementar (2009a).

Nota: Receita de contraprestações: Segundo a ANS, corresponde à soma das receitas a ela informada pelas operadoras. *As operadoras da modalidade autogestão passaram a informar suas receitas, obrigatoriamente, a partir de 2007.

Tabela 2 - Despesa total das operadoras por ano e crescimento (\%) segundo modalidade ( $\mathrm{R} \$$ milhões). Período: 2001-2008

\begin{tabular}{cccc}
\hline Modalidade & $\mathbf{2 0 0 1}$ & $\mathbf{2 0 0 8}$ & Crescimento (\%) \\
\hline Cooperativa Médica & 8.005 & 20.392 & 155 \\
\hline Medicina de Grupo & 6.154 & 16.049 & 161 \\
\hline Filantropia & 1.352 & 3.000 & 122 \\
\hline $\begin{array}{c}\text { Seguradora Especiali- } \\
\text { zada em Saúde }\end{array}$ & 5.022 & 9.991 & 99 \\
\hline Autogestão & 475 & 7.039 & $1382^{*}$ \\
\hline $\begin{array}{c}\text { Odontologia de } \\
\text { Grupo }\end{array}$ & 175 & 596 & 240 \\
\hline $\begin{array}{c}\text { Cooperativa Odonto- } \\
\text { lógica }\end{array}$ & 123 & 342 & 178 \\
\hline Setor & 21.307 & 57.410 & 169 \\
\hline
\end{tabular}

Fonte: Adaptado de Agência Nacional de Saúde Suplementar (2009a).

Nota: Segundo a ANS, a despesa é a ela informada pelas operadoras. *As operadoras da modalidade autogestão passaram a informar suas despesas, obrigatoriamente, a partir de 2007. 
Tabela 3 - Beneficiários de planos de saúde por cobertura assistencial de assistência exclusivamente odontológica e modalidade da operadora (Brasil - 2000-2008)

\begin{tabular}{ccc}
\hline \multirow{2}{*}{ Mês e ano } & \multicolumn{2}{c}{ Assistência exclusivamente odontológica } \\
\cline { 2 - 3 } & Cooperativa odontológica & Odontologia de grupo \\
\hline Dez./00 & 634.204 & 1.713 .042 \\
\hline Dez./01 & 780.664 & 1.968 .076 \\
\hline Dez./02 & 969.986 & 2.288 .252 \\
\hline Dez./03 & 1.139 .212 & 2.639 .137 \\
\hline Dez./04 & 1.291 .886 & 3.276 .918 \\
\hline Dez./05 & 1.470 .712 & 3.822 .577 \\
\hline Dez./06 & 1.658 .344 & 4.621 .486 \\
\hline Dez./07 & 1.839 .756 & 5.715 .494 \\
\hline Dez./08 & 2.085 .717 & 6.527 .649 \\
\hline
\end{tabular}

Fonte: Agência Nacional de Saúde Suplementar (2009b).

De acordo com Montone (2009), no início do processo regulatório por parte do governo brasileiro sobre as instituições que operam planos de saúde privados, cujo marco legal é a Lei $\mathrm{n}^{0}$ 9.656, de 3 junho de 1998, as operadoras odontológicas tinham pequeno poder de pressão em virtude de sua modesta participação no mercado, e como ainda houve, por parte desse tipo de operadora, resistência à regulação, acabaram sendo equiparadas às operadoras de assistência médica. Contudo, com o conhecimento do órgão regulador a respeito do setor e a consequente simplificação e aperfeiçoamento dos instrumentos regulatórios, os planos exclusivamente odontológicos expandiram-se.

Em relação ao crescimento do número de beneficiários de assistência médica com ou sem odontologia no período de 2000 a 2008 (Tabela 4), percebe-se que houve um aumento de $33,29 \%$, percentual bem acima do crescimento populacional no mesmo período que foi de 10,70\% (IBGE, 2009b).

No tocante ao desempenho das modalidades, verifica-se que as autogestões tiveram crescimento negativo de $0,94 \%$. As cooperativas médicas destacaram-se com aumento de $78,66 \%$ de seus usuários, enquanto as empresas de medicina de grupo e filantropia tiveram, respectivamente, $29,03 \%$ e 29,10\% de crescimento. Já as seguradoras especializadas em saúde cresceram $7,52 \%$.

Vários entrevistados relacionaram o crescimento de planos de saúde com o financiamento do SUS. Do ponto de vista deles, esse financiamento é insuficiente e, portanto, não garante a implementação adequada do sistema, incluindo o efetivo acesso aos serviços e, por conseguinte, as pessoas buscam o plano de saúde. Alguns naturalizaram esse problema, a exemplo da Confederação Nacional de Saúde: "Então esse sistema [SUS] foi se desenvolvendo, hoje nós não somos mais 
um país de 80 milhões de habitantes, são 200 milhões de habitantes. Volto a dizer os recursos do próprio Sistema Único são finitos [...]”.

Outros responsabilizaram o Estado e a sociedade, como o Conselho Nacional de Saúde no Jornal do CNS (2007):

[...] não é menos verdade as ameaças que pairam sobre a saúde pública e que vêm sendo rapidamente gestadas no seio de setores historicamente opostos ao SUS. Esse grupo refratário à regulamentação da Emenda Constitucional n. ${ }^{\circ} 29$ descumpre e contingência, solenemente, parcela considerável dos recursos federais e articula para alterar e diminuir o piso constitucional dos estados. Eles defendem também inserir, como gastos em saúde, rubricas de outras áreas sociais, o que significaria prejuízos incalculáveis na implementação de ações e serviços em saúde.

Apresentam-se na Tabela 5, extraída do Sistema de Informações sobre Orçamentos Públicos em Saúde (SIOPS), as despesas totais com ações e serviços públicos de saúde financiados com recursos próprios das três esferas de governo. Observa-se que o gasto com saúde no período 2000-2006 teve um incremento.

É sabido que a Emenda Constitucional $n^{\circ} 29$, que vinculou recursos das três esferas de governo à saúde, foi aprovada em 13 de setembro de 2000 e, embora a aprovação de sua regulamentação no Senado Federal só tenha ocorrido em 07 de dezembro de 2011, a Emenda possibilitou maior estabilidade ao financiamento

Tabela 4 - Beneficiários de planos de saúde por cobertura assistencial de assistência médica com ou sem odontologia e modalidade da operadora (Brasil - 2000-2008)

\begin{tabular}{ccccccc}
\hline & \multicolumn{5}{c}{ Assistência Médica com ou sem Odontologia } \\
\cline { 2 - 7 } Mês e ano & $\begin{array}{c}\text { Autoges- } \\
\text { tão }\end{array}$ & $\begin{array}{c}\text { Coope- } \\
\text { rativa } \\
\text { médica }\end{array}$ & $\begin{array}{c}\text { Filantro- } \\
\text { pia }\end{array}$ & $\begin{array}{c}\text { Medicina } \\
\text { de grupo }\end{array}$ & $\begin{array}{c}\text { Segu- } \\
\text { radora } \\
\text { especiali- } \\
\text { zada em } \\
\text { saúde }\end{array}$ & Setor \\
\hline Dez./00 & 5.256 .051 & 7.804 .737 & 1.107 .768 & 11.919 .732 & 4.603 .257 & 30.692 .434 \\
\hline Dez./01 & 5.199 .533 & 8.178 .619 & 1.101 .008 & 12.081 .539 & 4.586 .932 & 31.153 .545 \\
\hline Dez./02 & 5.211 .274 & 8.262 .735 & 1.070 .784 & 12.238 .334 & 4.340 .602 & 31.129 .527 \\
\hline Dez./03 & 5.032 .756 & 8.877 .376 & 997.683 & 12.057 .254 & 4.453 .993 & 31.424 .015 \\
\hline Dez./04 & 5.177 .816 & 9.693 .057 & 1.067 .257 & 13.221 .092 & 4.280 .165 & 33.444 .300 \\
\hline Dez./05 & 5.137 .342 & 10.768 .903 & 1.126 .300 & 14.132 .465 & 4.055 .137 & 35.220 .147 \\
\hline Dez./06 & 5.169 .963 & 11.877 .203 & 1.203 .779 & 14.875 .129 & 3.979 .743 & 37.105 .817 \\
\hline Dez./07 & 5.186 .377 & 12.964 .200 & 1.317 .077 & 15.258 .962 & 4.268 .321 & 38.994 .937 \\
\hline Dez./08 & 5.206 .505 & 13.944 .239 & 1.430 .219 & 15.380 .162 & 4.949 .506 & 40.910 .631 \\
\hline
\end{tabular}

Fonte: Agência Nacional de Saúde Suplementar (2009b). 
do sistema, marcado historicamente pela instabilidade de fontes de recursos. Contudo, ressalta-se que o valor em 2006 representa menos de 4\% do Produto Interno Bruto (PIB).

Tabela 5 - Despesa total das três esferas de governo com ações e serviços públicos de saúde financiada por recursos próprios. Período: 2000-2006

\begin{tabular}{|c|c|c|c|}
\hline Ano & Despesa (R\$ Milhões) * & Despesa por habitante* & $\%$ PIB \\
\hline 2000 & 34.035 & 200,44 & $2,89 \%$ \\
\hline 2001 & 40.032 & 232,22 & $3,07 \%$ \\
\hline 2002 & 47.035 & 269,34 & $3,18 \%$ \\
\hline 2003 & 53.329 & 301,51 & $3,14 \%$ \\
\hline 2004 & 65.130 & 363,64 & $3,35 \%$ \\
\hline 2005 & 73.993 & 401,73 & $3,45 \%$ \\
\hline 2006 & 84.033 & 449,93 & $3,60 \%$ \\
\hline
\end{tabular}

Fonte: Sistema de Informações sobre Orçamentos Públicos em Saúde (Siops) (BRASIL, 2009).

Nota: *Em 2000 e 2001 valores referem-se à despesa empenhada. Em 2002 e 2003, para a União e estados foram consideradas as despesas empenhadas. Para os municípios, a despesa liquidada. No período 2004-2006, para a União e Estados foram consideradas as despesas empenhadas. Para os municípios, a despesa empenhada excluindo-se os restos a pagar sem disponibilidade financeira. No âmbito federal foram excluídas despesas com inativos e pensionistas, com o pagamento de juros e amortização da dívida e com o Fundo de Erradicação e Combate à Pobreza.

Os gastos públicos em relação ao gasto total em saúde no Brasil, em 2006, representaram $45,30 \%$, contra $69,90 \%$ do Canadá, que também possui um sistema público universal (CONSELHO NACIONAL DE SECRETÁRIOS DE SAÚDE, 2007). Segundo Montone (2009), no Reino Unido, cujo sistema de saúde também é público e citado como modelo original do SUS, o gasto público representa $87 \%$ do gasto na saúde. Na relação de gastos públicos/privados, o país possui distribuição semelhante a dos Estados Unidos da América (EUA): 45,30\% / 54,70\% no caso do Brasil e 44,60\% / 56,40\% nos EUA, que possui, tradicionalmente, uma política de saúde de caráter liberal (CONSELHO NACIONAL DE SECRETÁRIOS DE SAÚDE, 2007).

Para Ugá e Marques (2005), os problemas de financiamento do SUS não advêm do seu modelo de sistema de saúde, mas estão atrelados à política de ajuste macroeconômico, cuja orientação compromete metade do gasto público com pagamento de juros, encargos e amortização das dívidas interna e externa. Em relação especificamente à forma de financiamento, o pesquisador 2 informou que havia uma divergência entre os sanitaristas: parte achava que o SUS deveria ter um financiamento nos moldes da Emenda Constitucional $n^{\circ}$ 29/2000, outra parte que o financiamento deveria ser originado no financiamento da seguridade social, sem financiamento exclusivo para a saúde. 
Entretanto, prevaleceu a primeira ideia que, no seu entender, autoriza ações governamentais benéficas para os planos de saúde, desde que haja o cumprimento dos percentuais fixos para o financiamento do SUS. Além disso, segundo ele, esses percentuais acabam tornando-se tetos, ou seja, percentuais máximos de aplicação, ao invés de se constituírem em referência mínima de despesa, o que contraria, de acordo com ele, o financiamento de um sistema universal que está sempre em expansão. Ressalta-se que a ideia de vinculação orçamentária também provocou forte resistência de lideranças do governo, a exemplo do Ministro da Fazenda (COSTA, 2002).

Nesse contexto, destaca-se a atuação do CFM, que realizou diversas manifestações em defesa do SUS e do respectivo financiamento adequado. Contudo, observaram-se nesta defesa componentes corporativistas, conforme declaração dada no Jornal Medicina, (O CFM..., 1999):

Veja bem: os planos e seguros-saúde cuidam apenas de 45 milhões de brasileiros. Somos 220 mil médicos. Se não tivéssemos nenhum outro motivo - e temos, que é o compromisso de que todos os cidadãos brasileiros tenham direito à saúde -, se não bastasse isso, sem o SUS não teríamos mercado de trabalho para 220 mil médicos. Independentemente de qualquer questão política ou ideológica, o SUS é indispensável para a população de nosso país e para a atividade dos nossos médicos.

Em seu estudo, Ribeiro (1993) também observou no sindicalismo médico a prática de participação desses profissionais em experiências de defesa de interesses gerais, nas quais se tenta convencer a população de benefícios coletivos de demandas que são, na verdade, individuais.

A CUT apontou o caráter corporativista do CFM. Todavia, observou-se no estudo o papel contraditório da central sindical na defesa do SUS, pois à medida que no âmbito macro político a entidade mobiliza-se para a defesa do SUS, os sindicatos a ela ligados lutam por contratação de planos de saúde para seus filiados: "Então você tem uma posição política ideológica nos fóruns contra a privatização da saúde, defesa da implantação do SUS, da prioridade pro SUS, mas vc tem uma prática cotidiana que a base exige [...] você contratar planos de saúde".

Ressalta-se que na base a qual a CUT refere-se estão também os funcionários públicos, incluindo os trabalhadores do SUS que, muitas vezes, contratam planos de saúde privados com apoio financeiro do Estado. É preciso, segundo o pesquisador 1, discutir com os trabalhadores organizados sobre o financiamento da saúde com o fim de fortalecer o projeto do Sistema Único de Saúde. Para o pesquisador 2, os trabalhadores, incluindo os trabalhadores da saúde, não apoiaram o SUS.

Os planos e seguros de saúde cobrem predominantemente uma parcela da população de cor branca, maior renda familiar, maior escolaridade, inseridas em 
determinadas atividades do mercado de trabalho e moradores de capitais/regiões metropolitanas, nas quais o acesso e o número de prestadores (clínicas, hospitais) por operadora é maior do que se constata nos municípios com menos de 80 mil habitantes (PINTO, 2004). Desse modo, os grupos cobertos pelos planos de saúde são a população economicamente ativa e com vocalização política. Para o pesquisador 1 é justamente essa composição da clientela que torna o mercado importante, sendo menos importante a quantidade de usuários cobertos.

\section{Renúncia Fiscal}

Outra forma existente no Brasil de financiar a saúde é por meio da renúncia de arrecadação fiscal feita pelo Estado em benefício direto dos declarantes do imposto de renda, quando esses informam despesas próprias com saúde ou despesas com a saúde de seus empregados. Tais benefícios são vistos por vários entrevistados como incentivos governamentais ao mercado de planos de saúde e promotores de iniquidade.

A seguir, a Tabela 6 demonstra os valores declarados por pessoas físicas e jurídicas com despesas de saúde, dentre elas gastos com planos de saúde. Observase que no período de 1998 a 2003 houve um crescimento de 127,25\% dos gastos declarados por pessoa física, enquanto os de pessoa jurídica cresceram 36,29\%.

Tabela 6 - Gastos declarados com despesas médicas por ano segundo natureza do declarante ( $\mathrm{R} \$$ milhões)

\begin{tabular}{|c|c|c|c|c|c|c|}
\hline \multirow{2}{*}{$\begin{array}{c}\text { Natureza } \\
\text { do decla- } \\
\text { rante }\end{array}$} & \multicolumn{6}{|c|}{ Anos } \\
\hline & 1998 & 1999 & 2000 & 2001 & 2002 & 2003 \\
\hline $\begin{array}{c}\text { Pessoa Física } \\
\text { (PF) }\end{array}$ & 8.908 & 10.740 & 13.475 & 15.828 & 15.467 & 20.244 \\
\hline $\begin{array}{c}\text { Pessoa Jurí- } \\
\text { dica (PJ) * }\end{array}$ & 3.422 & 3.236 & 3.334 & 3.744 & 4.333 & $4.664^{1}$ \\
\hline
\end{tabular}

Fonte: Secretaria da Receita Federal (BRASIL, 2000a, 2000b, 2002a, 2002b, 2003a, 2003b, 2003c, 2004, 2006, 2007, 2008).

Nota: * Os valores referem-se ao somatório das seguintes PJ: "PJ em geral e corretoras + Instituições financeiras + seguradoras" 1 - Os valores referem-se ao somatório das seguintes PJ: "PJ em geral e corretoras + Instituições financeiras"

Para o pesquisador 2, o mercado sempre foi financiado com recursos públicos. Inicialmente com dinheiro da Previdência Social e depois, como ocorre atualmente, por meio dos benefícios tributários que, segundo ele, expandem artificialmente o mercado. Exemplifica dizendo que nas décadas de 1980 e 1990 não houve crescimento econômico no Brasil e, no entanto, houve crescimento dos planos de saúde. 
Em estudo, Andreazzi, Sicsú e Holguin (2008) encontraram valores estimados decrescentes de benefícios tributários para o mesmo período do presente trabalho. Porém, este estudo analisou os valores declarados. Embora possa ter importância o valor renunciado pelo Estado brasileiro, é mais significativa a decisão governamental de continuidade do benefício tributário ao mercado de planos de saúde, ao mesmo tempo em que há um pequeno aumento do financiamento ao SUS.

Do ponto de vista dos representantes de planos de saúde, a renúncia compensa a incapacidade do Estado na oferta de serviço de saúde à população e, portanto, desonera o SUS, já que segmentos populacionais são atendidos pelos serviços privados e não pelo SUS. Além disso, segundo esses representantes, é meritório o uso do benefício tributário, comparando com os que não contratam planos de saúde, já que as necessidades das pessoas são diferentes. Disso é ilustrativa a fala da Abramge: "Acho que ela [renúncia fiscal] beneficia a equidade uma vez que essas pessoas, que têm necessidades diferenciadas, elas têm, elas podem ser tratadas de uma maneira diferenciada". Verifica-se aqui que o conceito de equidade adotado não se constitui em princípio norteador para transformação da realidade social desigual (DUARTE, 2000). Ao contrário, postula o mérito de um grupo de indivíduos no acesso exclusivo a benefícios governamentais, a partir da posição ocupada por eles na estrutura social.

No cenário imaginário de extinção da renúncia fiscal, alguns atores acreditam que haveria sérias consequências negativas para o mercado com consequente migração dos usuários para o SUS; já outros acreditam que não haveria abalos significativos para o setor de planos de saúde. Em estudos realizados tanto nos EUA quanto na Europa observou-se que o fim de benefícios tributários relacionados às despesas com saúde feitas por famílias e empresas não repercutiu proporcionalmente na diminuição da demanda por serviços privados de saúde. Além disso, no caso brasileiro, com a extinção da renúncia fiscal poderia ocorrer situação como, por exemplo, de favorecimento de empresas empregadoras de mercados menos competitivos, com lucros extraordinários ou com mão de obra reduzida, pois essas possivelmente absorveriam melhor o impacto das despesas efetuadas com a saúde de seus empregados (ANDREAZZI; SICSÚ; HOLGUIN, 2008).

$\mathrm{Na}$ mesma linha, o pesquisador 1 chama a atenção para o fato de que é possível que a extinção desses benefícios tributários, em curto prazo, favoreça as operadoras de planos de saúde líderes, já que são as entidades com porte econômico capaz de suportar melhor esse impacto. $O$ pesquisador informa ainda que a extinção da renúncia fiscal deve vir acompanhada de outras medidas, fato também alertado pelo Idec.

Em relação ao argumento de desoneração do SUS, ele se mostra mais adequado para justificar uma forma de financiamento da saúde do que efetivamente 
para expressar a realidade. Tal argumento baseia-se no melhor aproveitamento dos recursos do SUS para atendimento de uma parte da população, já que a outra parte é assistida pelo mercado de planos de saúde, sendo esta compensada pelo benefício tributário, da incapacidade do Estado de ofertar saúde a toda a população.

Sabe-se, porém, por dados da Pesquisa Nacional por Amostra de Domicílio PNAD 2003 (IBGE, 2009a), que as pessoas que melhor autoavaliaram o seu estado de saúde eram cobertas pelos planos que, portanto, não cuidam dos mais doentes, o que torna o argumento da desoneração do SUS questionável.

Além disso, sabe-se que os usuários de planos de saúde têm a possibilidade formal de utilizar o SUS para obter procedimentos que, por lei, os planos não são obrigados a ofertar. É sabido ainda que os custos dos empregadores com despesas de saúde dos funcionários podem ser repassados aos preços dos produtos. Desse modo, para o pesquisador 1, ocorre uma socialização dos custos dos planos de saúde: "O mercado tem interesse que um determinado tipo de SUS continue funcionando [...] onde o mix público/privado atenda seus pressupostos mercantis".

\section{Considerações Finais}

O estudo aponta para o crescimento do mercado brasileiro de planos de saúde no período de 1990 a 2008, expresso pelo aumento significativo do número de pessoas a ele vinculadas e pelos depoimentos das instituições componentes desse mercado e dos pesquisadores entrevistados. $\mathrm{O}$ crescimento da receita menor que o da despesa pode indicar, entretanto, que haja desequilíbrio econômico nesse crescimento. Pressões de custos crescentes são características de sistemas de saúde e, portanto, são encontradas em todas as modalidades de compartilhamento de risco e formas de asseguramento, sobretudo naqueles cuja provisão é orientada por diretrizes de mercado, como as empresas de planos de saúde suplementar.

Ao mesmo tempo, o estudo verificou o incremento da renúncia fiscal referente às despesas médicas, além do pequeno aumento de gastos diretos na saúde em relação ao PIB, em conformidade com as reformas ocorridas na política de saúde dos países, as quais direcionaram esse setor para a iniciativa privada.

Entretanto, a discussão do crescimento do mercado brasileiro de planos de saúde e suas relações com o financiamento do SUS e com a renúncia fiscal referente às despesas médicas ultrapassam os limites setoriais da política de saúde, devendo ser o tema abordado de forma abrangente sob pena de empobrecer o debate e fragilizar a luta por um sistema público e universal de saúde. 


\section{Referências}

AGÊNCIA NACIONAL DE SAÚDE SUPLEMENTAR (Brasil). ANS TabNet. Receita de contraprestações e despesas. 2009a. Disponível em: < http://www.ans.gov.br/anstabnet/anstabnet/deftohtm.exe?anstabnet/dados/TABNET_RC.DEF> . Acesso em: 30 mar. 2009.

. Caderno de informação da saúde suplementar: beneficiários, operadoras e planos. 2. ed. rev. atual. Rio de Janeiro, 2009b.

ANDRADE, M. V. Financiamento do setor de saúde suplementar no Brasil: uma investigação empírica a partir dos dados da PNAD/98. In: MONTONE, J.; CASTRO, A. J. W. (Org.). Regulação 8 saúde: documentos técnicos de apoio ao Fórum de Saúde Suplementar de 2003. Rio de Janeiro: Ministério da Saúde, 2004. v. 3, tomo 1.

ANDREAZZI, M. F. S.; SICSÚ, B.; HOLGUIN, T. Gastos tributários relacionados ao consumo de atenção privada a saúde: contribuição ao debate sobre políticas de financiamento. São Paulo em Perspectiva, São Paulo, v. 22, n. 1, p. 137-151, 2008.

BAHIA, L. O SUS e os desafios da universalização do direito à saúde: tensões e padrões de convivência entre o público e o privado no sistema se saúde brasileiro. In: LIMA, N. T. et al. (Org.). Saúde e democracia: história e perspectivas do SUS. Rio de Janeiro: Fiocruz, 2005. p. 407-449.

BARDIN, L. Análise de conteúdo. Lisboa: Edições 70, 2004.

BRASIL. Departamento de Informática do SUS. Sistema de informações sobre orçamentos públicos em saúde. Disponível em: < http://siops.datasus.gov.br/>. Acesso em: 20 mar. 2009.

Secretaria da Receita Federal. Coordenação-Geral de Estudos Econômico Tributários. Análise econômica da DIRPF 1999. 2000a. (Texto para discussão, 9). Disponível em: <http://www.receita.fazenda.gov.br/Publico/estudotributarios/estatisticas/11AnaliseEconom icaDIRPF1999.pdf > . Acesso em: 16 jul. 2009.

. Consolida DIPJ 1999: Consolidação da Declaração de Informações Econômico - Fiscais das Pessoas Jurídicas de 1999. Brasília, DF, 2000b. (Estatísticas Tributárias, 2). Disponível em: <http://www.receita.fazenda.gov.br/Publico/estudotributarios/estatisticas/12\%20Consolida\%20DIPJ\%201999.pdf> . Acesso em: 28 jul. 2009.

. Secretaria da Receita Federal. Coordenação-Geral de Política Tributária. Consolida DIPJ 2000: consolidação da declaração de informações econômico-fiscais das pessoas jurídicas de 2000. 2002a. (Estatísticas Tributárias, 4). Disponível em: < http://www.receita.fazenda.gov.br/Publico/estudotributarios/estatisticas/21\%20Consolida\%20DIPJ\%202000.pdf> . Acesso em 28 jul.2009.

. Consolida DIPJ 2001: Consolidação da Declaração do Imposto de Renda das Pessoas Jurídicas - 2001. 2003a. (Estatísticas tributárias, 6). Disponível em: <http://www.receita.fazenda.gov.br/Publico/estudotributarios/estatisticas/24\%20Consolida\%20DIPJ\%202001.pdf>. Acesso em: 16 jul. 2009.

. Consolida DIPJ 2002: Consolidação da Declaração do Imposto de Renda das Pessoas Jurídicas - 2002. 2003b. (Estatísticas tributárias, 7). Disponível em: < http://www.receita.fazenda.gov.br/Publico/estudotributarios/estatisticas/27\%20Consolida\%20DIPJ\%202002.pdf> . Acesso em: 28 jul. 2009.

. Consolida DIPJ 2003: Consolidação da Declaração do Imposto de Renda das Pessoas Jurídicas - 2003. 2004. (Estatísticas tributárias, 10). Disponível em: < http://www.receita.fazenda.gov.br/Publico/estudotributarios/estatisticas/30ConsolidaDIPJ2003\%20.pdf > . Acesso em: 28 jul. 2009. 
BRASIL. Consolida DIRPF 2001: Consolidação das Declarações do Imposto de Renda das Pessoas Físicas - 2001. 2002b. (Estatísticas tributárias, 5). Disponível em: <http://www.receita.fazenda.gov.br/Publico/estudotributarios/estatisticas/22\%20Consolida\%20DIRPF\%20 2001.pdf>. Acesso em: 16 jul. 2009.

. Consolida DIRPF 2002: Consolidação da Declaração do Imposto de Renda das Pessoas Físicas - 2002. 2003c. (Estatísticas tributárias, 9). Disponível em: <http://www.receita. fazenda.gov.br/Publico/estudotributarios/estatisticas/29ConsolidaDIRPF2002.pdf > . Acesso em: 17 jul. 2009.

. Consolida DIRPF 2003: Consolidação da Declaração do Imposto de Renda das Pessoas Físicas - 2003. 2007. (Estatísticas tributárias, 12). Disponível em: <http://www.receita. fazenda.gov.br/Publico/estudotributarios/estatisticas/ConsolidaDirpf2003.pdf > . Acesso em: 17 jul. 2009.

. Consolida DIRPF 2004: Consolidação da Declaração do Imposto de Renda das Pessoas Físicas - 2004. 2008. (Estatísticas tributárias, 13). Disponível em: <http://www.receita. fazenda.gov.br/Publico/estudotributarios/estatisticas/ConsolidaDirpf2004.pdf > . Acesso em: 18 jul. 2009.

. Grandes números DIRPF - 2000 a 2003. 2006. Disponível em: <http://www.receita. fazenda.gov.br/Publico/estudotributarios/estatisticas/GrandesNumerosIRPF2000-2003.pdf > . Acesso em: 17 jul. 2009.

CONSELHO NACIONAL DE SECRETÁRIOS DE SAÚDE (Brasil). Saúde suplementar. Brasília, DF, 2007. (Pró-gestores: para entender a gestão do SUS).

COSTA, R. C. R. Descentralização, financiamento e regulação: a reforma do sistema público de saúde no Brasil durante a década de 1990. Revista de Sociologia e Política, Curitiba, n.18, p. 49-71, jun. 2002.

DUARTE, C. M. R. Equidade na Legislação: um princípio do sistema de saúde brasileiro? Ciência E Saúde Coletiva, Rio de Janeiro, v. 5, n. 2, p. 443-463, 2000.

IBGE. Pesquisa nacional por amostra de domicílios 2003 (Corpo básico e suplemento acesso e utilização de serviços de saúde). Disponível em: <http://www.ibge.gov.br/lojavirtual/fichatecnica.php?codigoproduto $=8427>$. Acesso em: 6 jul. 2009 a.

. Projeção da população do Brasil por sexo e idade: 1980 - 2050: revisão 2008. Disponível em: <http://www.ibge.gov.br/home/estatistica/populacao/projecao_da_populacao/2008/default.shtm>. Acesso em: 24 ago. 2009b.

JORNAL DO CNS. Brasília, DF: Conselho Nacional de Saúde, jan./abr. 2007. Disponível em: <http://conselho.saude.gov.br/biblioteca/jornaicns/12.pdf>. Acesso em: 24 ago. 2009.

MONTONE, J. Planos de saúde: passado e futuro. 10 anos da lei geral dos planos de saúde. Rio de Janeiro: Medbook, 2009.

O CFM, os médicos e a sociedade. Jornal Medicina, Brasília, DF, jun. 1999. Disponível em: <http://www.portalmedico.org.br/jornal/jornais1999/0699/entrevista.htm>. Acesso em: 20 dez. 2009.

PEREIRA FILHO, C. E. F. O marco regulatório no setor de saúde suplementar: contextualização de perspectivas. In: MONTONE, J. ; CASTRO, A. J. W. (Org.). Regulação e saúde: documento técnicos de apoio ao Fórum de Saúde Suplementar de 2003. Rio de Janeiro: Ministério da Saúde, 2004. v. 3, t. 1. 
PINTO, L. F. S. O setor de saúde suplementar: acesso e cobertura populacional. In: MONTONE, J.; CASTRO, A. J. W. (Org.). Regulação e saúde: documento técnicos de apoio ao Fórum de Saúde Suplementar de 2003. Rio de Janeiro: Ministério da Saúde, 2004. v. 3, t. 1.

PORTO, S. M.; SANTOS, I. S.; UGÁ, M. A. D. O mix público-privado no Sistema de Saúde Brasileiro: financiamento, oferta e utilização de serviços de saúde. Ciência $\mathcal{J}$ Saúde Coletiva, Rio de Janeiro, v. 13, n. 5, p. 1431-1440, 2008.

RIBEIRO, J. M. Arranjos neocorporativos e defesa de interesses dos médicos. Cadernos de Saúde Pública, Rio de Janeiro, v. 9, n. 1, p. 5-20, jan./mar. 1993.

UGÁ, M. A. D.; MARQUES, R. M. O financiamento do SUS: trajetória, contexto e constrangimentos. In: LIMA, N. T. et al. (Org.). Saúde e democracia: história e perspectivas do SUS. Rio de Janeiro: Fiocruz, 2005. p. 193-234.

\section{Anexo A - Roteiro da Entrevista}

\section{Financiamento do SUS}

1- Como o(a) Senhor(a) vê a relação entre o mercado brasileiro de planos de saúde e a implementação do SUS (financiamento, fatos, qualidade da atenção à saúde do SUS, etc.)?

2- Como o(a) Senhor(a) vê a relação entre o financiamento do SUS e o crescimento do mercado brasileiro de planos de saúde?

Mercado de planos privados de saúde

1- Como o (a) Senhor (a) vê a atuação dos atores (governo: MS, ANS, MF/ Receita Federal/Susep; usuários: Idec e CUT; operadoras: Abramge, Unimed, Unidas, Fenasaúde; prestadores: Confederação Nacional de Saúde e Conselho Federal de Medicina; e Conselho Nacional de Saúde) no comportamento do mercado brasileiro de planos de saúde a partir de 1990?

2- Qual a sua opinião sobre a relação entre a regulação brasileira do mercado de planos de saúde e o comportamento deste mercado a partir de 1998 ?

Renúncia fiscal

1. Como o (a) Senhor (a) relaciona o crescimento do mercado brasileiro de planos de saúde e a renúncia fiscal?

2. Comente acerca da relação entre a renúncia fiscal e a promoção da equidade na política de saúde. 
3. O que o (a) Senhor (a) acha que aconteceria ao mercado de planos e à política de saúde caso a renúncia fiscal fosse extinta (explorar as implicações para a classe média, empresas)?

Recebido em: 15/01/2012. Aceito em: 26/06/2012. 